\title{
ERJ
}

Engineering Research Journal

Faculty of Engineering

Minoufiya University

\section{TRANSIENT CHARACTERISTICS OF CYLINDRICAL STATOR 6/2 SWITCHED RELUCTANCE GENERATOR}

\author{
F. M. El-Khouly \\ Electrical Engineering Department, \\ Faculty of Engineering, \\ Minoufiya University, Egypt
}

\author{
A. F. Abdel-Kader \\ Agriculture Ministry \\ Tanta Strip
}

\begin{abstract}
The switched reluctance motor can be used in generation mode by selecting the firing angles of the phases. Switched reluctance generators have been identified as a potential option for military aircraft, variable speed wind turbine and automotive electric power systems. Switched reluctance generator (SRG) has various desirable features which include simple and solid structure, easiness of maintenance, small moment of rotor inertia and low cost.

This paper presents detailed transient characteristics of a $6 / 2$ cylindrical stator switched reluctance generator (SRG) through experimental observation. The results are computed from the transient analysis equations. The computed results are presented to validate the effectiveness. Due to highly nonlinear characteristics of (SRG), iterative simulation of the generator model on the range of parameters and control variables has been used.

Maximization of (SRG) output power has been addressed in this paper. Phase self-inductance, phase voltage switching angles, DC excitation voltage level and shaft speed of the generator have been identified as control variables affecting output power. Depending on the application each one can be defined as control variable.

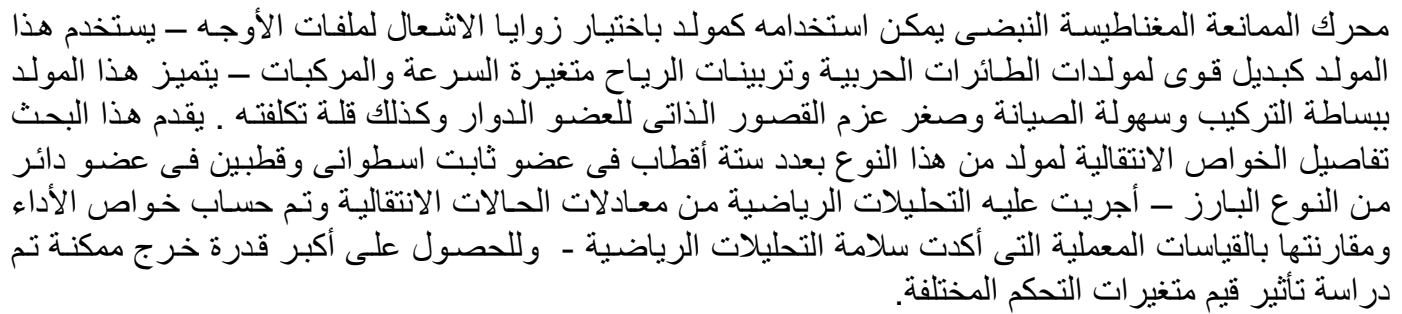

Keywords: Reluctance generator, Generator control, Wind energy generator, Aircraft generator, Automotive generator, Variable speed generator

\section{INTRODUCTION}

The switched reluctance machine has been studied extensively during the last years [1-7]. The machine can be applied not only as a motor, but also as a generator [2-6]. The switched reluctance generator (SRG) system consists of the switched reluctance generator, the power converter and the controller. The (SRG) has desirable features including simple and solid construction, easiness of maintenance, small moment of inertia and low cost. This is because the (SRG) has no rotor windings and no permanent magnet. The solid rotor construction is useful for ultra high speed generator such as a micro gas turbine generator. On the other hand, simple structure and small moment of inertia suit a low speed multi-polar generator for use in wind turbine generation $[3,4,11]$. Several papers have reported on the application of switched reluctance machine to a generator [1 - 13].
The (SRG) is an attractive solution for worldwide increasing demand of electrical energy. It is low cost, fault tolerant with a rugged structure and operates with high efficiency over a wide speed range. Merits of using SRG have been proved for some applications like starter/generator for gas turbine of aircrafts $[1,2,5]$, windmill generator $[3,4]$ and as an alternator for automotive applications [5]. The major issue in the stand-alone generator is power-density maximization, that is, maximum power output for a given power rating. In other words, minimal sizing and lighter weight in the same rated machine are the most important factors. Thus, understanding characteristics of (SRG) for maximization of output power of generator in design and control is an important point for utilizing it for more and more applications. Generating mode of switched reluctance machine has been one of the research topics recently [1-4]. In [6], Principle of operation of (SRG) has been presented and the necessity for closed loop control is proved. In [7], the control of excitation of 
(SRG) for maximum efficiency at single pulse mode of operation has been presented. Turn on and turn off angles are defined as control variables. Turn on angle is set based on the output power and the turn off angle is selected to achieve optimal efficiency at each power level and speed.

Closed-loop control of a switched reluctance machine is difficult because of the severe nonlinear magnetic properties. To control the applied DC excitation voltage of a SRG, an application of linearising control based on an inverse machine model has been presented in [2]. Other methods like tolerance band controller and PI controller can be also applied [4], but the design of the controllers depend closely on the precise characteristics of the machine. In recent years fuzzy logic control has been used in motor drive systems, such as induction servo drive and even in switched reluctance motor [7]. The design of fuzzy logic control is based on linguistic rules, which depend more on expert knowledge of the designer instead on the precise characteristics of the machine [7].

In this paper, cylindrical stator $6 / 2$ switched reluctance generator shown in Fig. 1 is investigated.

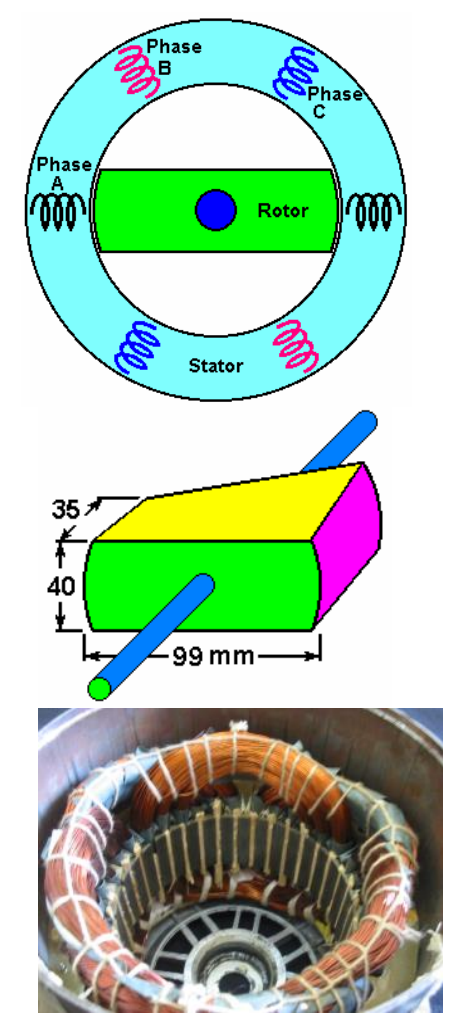

Fig. 1 Construction of the (SRG)

The generator has been built to execute practical experiments. Stator is chosen to be cylindrical sheet poles, not salient poles. Stator is consisted of six poles. Each two opposite poles construct one phase. So, the stator consists of three phases A, B and C. There is $60^{\circ}$ space angle between each phase and its adjacent phase. The rotor has two salient poles without any winding. The rotor length has the same lamination length of stator. In order to decrease the harmonics of stator slots, the rotor is skewed by stator slot pitch as shown in Fig. 1.

\section{OFDM SYSTEM MODEL CONVERTER TOPOLOGY}

SRG drive Converter, should be able to magnetize phase coils, retrieve the generated power and demagnetize the phase coils in each cycle. An initial converter topology for this purpose is half bridge inverter $[6,8,10]$ as shown in Fig. 2.

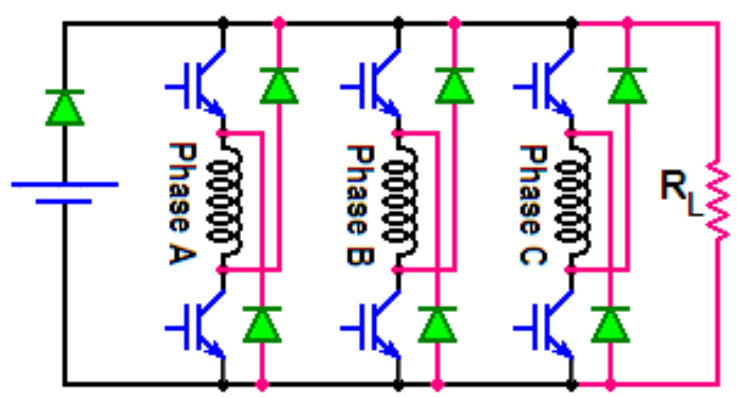

Fig. 2 Classical converter topology

Figure 3 shows a conventional excitation circuit of the SR generator using an asymmetry half bridge converter (AHBC). In this converter, one diode is removed from the initial converter. The opposed two transistors turn on and turn off at the same moment against the appropriate rotor position angle. The stator pole is excited and its winding current increases when the transistors turn on. When the transistors turn off, the current flows through the external load resistance $R_{L}$ and the generated electric power is supplied to the load resistance $[8,10,13]$.

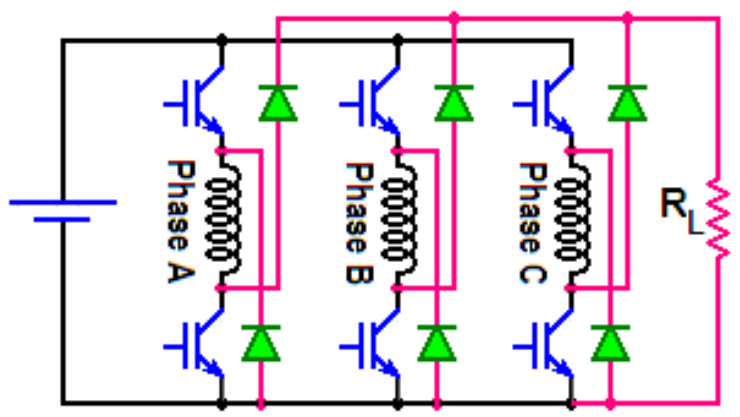

Fig. 3 An asymmetry half bridge converter

The circuit of AHBC is somewhat complicate because AHBC needs two transistors and two diodes per phase. In order to reduce the number of the devices, a suppression resistor converter (SCR) is presented [13].

Figure 4 shows a circuit configuration of the reduced devices converter. Figure 5 shows an explanation of the circuit operation of the reduced devices converter per phase. When the transistor 
turns on, the stator phase is excited. The current flows through the load resistance when the transistor turns off.

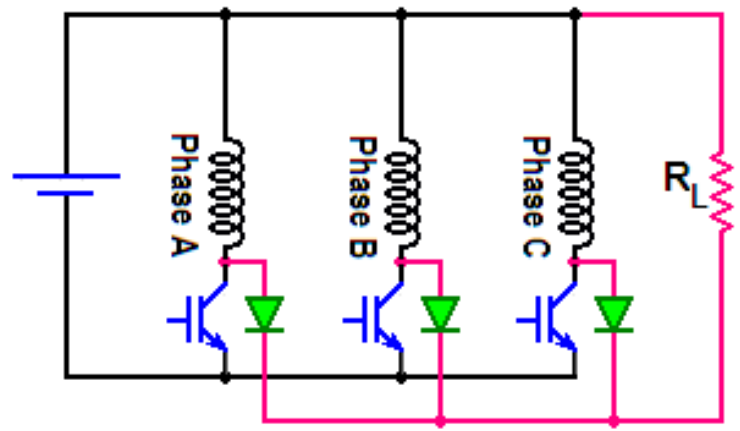

Fig. 4 Reduced devices converter

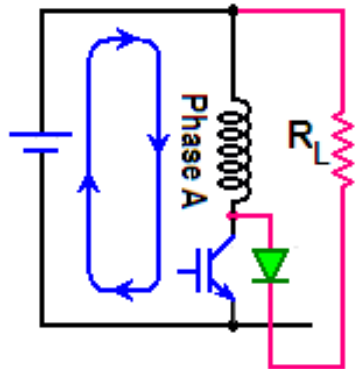

(a) Exciting mode.

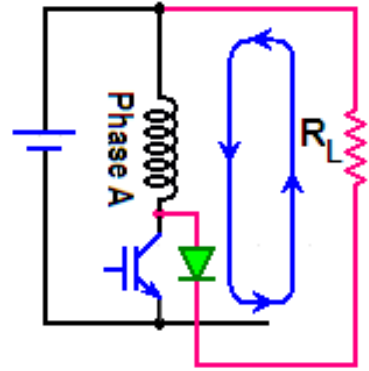

(b) Generating mode.
Fig. 5 Circuit operation of the converter

When the controllable switches are closed, current builds in the SRG phase winding. For generator operation, excitation generally begins near the aligned position for relatively low-speed operation. The excitation is often advanced with increasing speed so that excitation begins before the aligned position. This is analogous to the advance introduced in the control of the SRG. After the controllable switches are turned off, more energy is returned to the source than was provided for excitation.

In the converters of Figs. 2, 3, 4; the load currents will be overlapped and the higher current switches off the lower currents. For continuity of load phases current and higher load power, the load resistance is divided on the three phase as shown in Fig. 6.

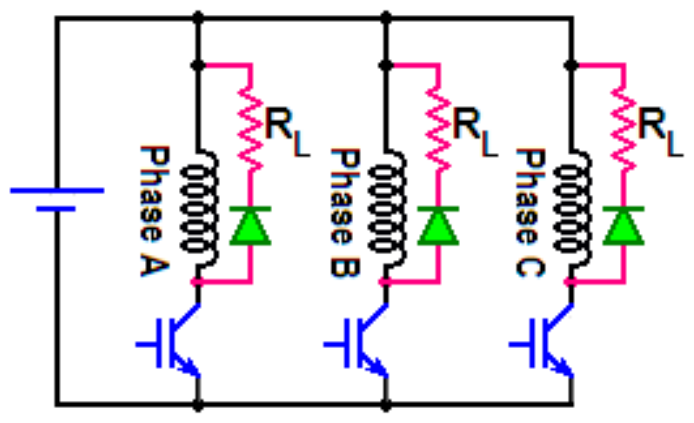

Fig. 6 Divided load resistance
The converter topology of Fig. 6 is used in the analysis and computed characteristics of this work.

\section{PERFORMANCE ANALYSIS}

\subsection{Generator Voltage Equation}

The voltage equation for each phase $\left(\mathbf{V}_{\mathbf{p h}}\right)$ of SRG is given $[4,5,9,10,12]$ by

$$
V_{\text {ph }}=I_{\text {ph }} R_{\text {ph }}+\{\mathbf{d} \lambda / \mathbf{d} \mathbf{t}\}
$$

If the effects of saturation are neglected this expression can be rewritten as:

$$
V_{p h}=I_{p h} R_{p h}+\left\{d\left(L_{p h} I_{p h}\right) / d t\right\}
$$

In generation mode of the operation (2) can be modified to the following form in which the even symmetry of the inductance profile is taken into account.

$$
\begin{aligned}
& V_{p h}=I_{p h} R_{p h}+\left\{L_{p h}\left(d I_{p h} / d t\right)\right\}+ \\
& \left\{I_{\text {ph }}\left(d L_{\text {ph }} / d t\right)\right\} \text { or } \\
& V_{p h}=I_{p h} R_{p h}+\left\{L_{p h}\left(d I_{p h} / d t\right)\right\}+ \\
& \left\{I_{\text {ph }}\left(d L_{\text {ph }} / d \theta\right)(d \theta / d t)\right\} \text { and } \\
& \mathbf{V}_{\text {ph }}=I_{\text {ph }} R_{\text {ph }}+\left\{L_{\text {ph }}\left(d I_{\text {ph }} / d t\right)\right\}+ \\
& \left\{\omega I_{\mathrm{ph}}\left(\mathrm{dL} \mathrm{ph}_{\mathrm{ph}} / \mathrm{d} \theta\right)\right\}
\end{aligned}
$$

Where $\mathbf{V}_{\mathbf{p h}}, \mathbf{I}_{\mathbf{p h}}, \mathbf{L}_{\mathbf{p h}}, \boldsymbol{\theta}, \boldsymbol{\omega}$ and $\mathbf{R}_{\mathbf{p h}}$ stand for phase voltage, phase current, phase inductance, rotor position angle with respect to the axis of phase A, speed and stator resistance, respectively.

Thus;

$$
V_{p h}=I_{p h} R_{p h}+E_{S}+E_{R}
$$

Where; The self e.m.f. $\left(E_{S}\right)$ is

$$
E_{S}=L_{p h}\left(d I_{p h} / d t\right)
$$

And the rotational e.m.f. $\left(E_{R}\right)$ is

$$
E_{R}=\omega I_{p h}\left(d L_{p h} / d \theta\right)
$$

\subsection{Calculation of Generator Torque}

The generator torque is obtained from the effect of direct current passing on stator phases and the changing of rotor reluctance. The instantaneous value of torque is proportional with square of instantaneous current also with rate of phase inductance variation with respect to rotor angle $(\mathrm{dL} / \mathbf{d \theta})$; or the inductance curve deviation with rotor angle $\boldsymbol{\theta}$. When 
this inductance derivation is positive, the torque is positive which lead to rotor rotation in motoring mode. But if the inductance derivation is negative, the torque will be negative, which needs the prime mover to push the rotor to rotate in the same direction of motoring rotation.

The instantaneous value of generator torque, resulting from each of three phases is determined as follows $[1,5,9,13]$;

$$
\begin{aligned}
& T_{A}=0.5 \mathrm{I}_{\mathrm{A}}{ }^{2} \mathrm{~d} \mathrm{~L}_{\mathrm{A}} / \mathrm{d} \theta \\
& \mathrm{T}_{\mathrm{B}}=0.5 \mathrm{I}_{\mathrm{B}}{ }^{2} \mathrm{~d} \mathrm{~L}_{\mathrm{B}} / \mathrm{d} \theta \\
& \mathrm{T}_{\mathrm{C}}=0.5 \mathrm{I}_{\mathrm{C}}{ }^{2} \mathrm{~d} \mathrm{~L}_{\mathrm{C}} / \mathrm{d} \theta
\end{aligned}
$$

The instantaneous generator total torque $\left(\mathbf{T}_{\text {total }}\right)$ is

$$
\mathbf{T}_{\text {total }}=\mathbf{T}_{\mathrm{A}}+\mathbf{T}_{\mathrm{B}}+\mathbf{T}_{\mathrm{C}}
$$

\subsection{Phase Inductance Calculation}

The experimental generator phase self inductance is measured at different phase currents to give its variation due to rotor saliency. Neglecting the effect of saturation on the values of inductance, a suitable mean curve for each phase inductance is shown in Fig. 7.

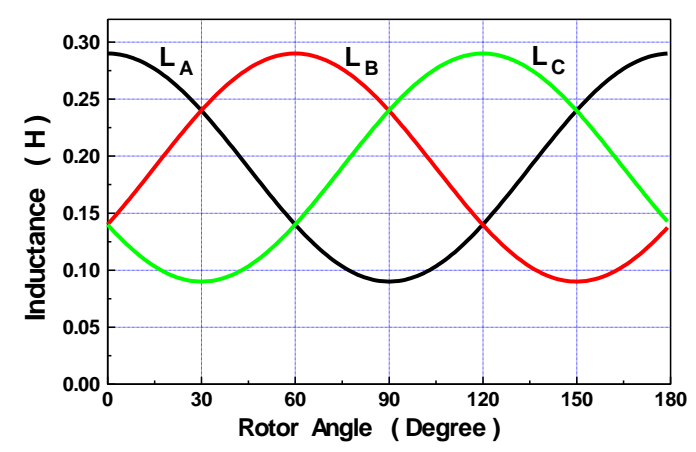

Fig. 7 Variation of generator inductances with rotor position

From this figure, the variation of inductance with rotor angle is nearly sinusoidal wave added to a constant value. Thus, the self inductance for each phase is determined from the following equations

$$
\begin{aligned}
& L_{A}=L_{q}+L_{0}+L_{0} \cos (2 \theta) \\
& L_{B}=L_{q}+L_{0}+L_{0} \cos \left(2\left(\theta+2 \theta_{s}\right)\right) \\
& L_{C}=L_{q}+L_{0}+L_{0} \cos \left(2\left(\theta+\theta_{s}\right)\right)
\end{aligned}
$$

Where;

$$
\text { Lo }=\left(\mathbf{L}_{\mathbf{d}}-\mathbf{L}_{\mathbf{q}}\right) / 2 \text {; }
$$

$\mathbf{L}_{\mathbf{d}}$ is the stator phase inductance at aligned position;

$\mathbf{L}_{\mathbf{q}}$ is the stator phase inductance at unaligned position.
The derivation of phases inductance with respect to rotor position will be;

$$
\begin{aligned}
& \mathrm{dL}_{\mathrm{A}} / \mathrm{d} \theta=-2 \mathrm{Losin}(2 \theta) \\
& \mathrm{dL}_{\mathrm{B}} / \mathrm{d} \theta=-2 \mathrm{Lo} \sin \left(2\left(\theta+2 \theta_{\mathrm{s}}\right)\right) \\
& \mathrm{dL}_{\mathrm{C}} / \mathrm{d} \theta=-2 \mathrm{Lo} \sin \left(2\left(\theta+\theta_{\mathrm{s}}\right)\right)
\end{aligned}
$$

Where; $\boldsymbol{\theta}_{\mathrm{s}}$ is the angle between each two sequential stator phases $=60$ degree.

\subsection{Phase Current Calculation}

The instantaneous value of stator phase excitation current ( $\mathbf{I}_{\mathbf{p h}}$ ) during the excitation period is determined from the following equation [11];

$$
\left.\mathbf{I}_{\mathrm{ph}}=\mathbf{I}_{\max }\left[\mathbf{1}-\mathbf{e}^{-(\mathrm{t} /} \boldsymbol{\tau}\right)\right]
$$

Where;

$$
\mathbf{I}_{\max }=\left(\mathbf{V}_{\mathrm{ph}}-\mathbf{E}_{\mathbf{R}}\right) / \mathbf{R}_{\mathrm{ph}}
$$

When the rotor angle $(\boldsymbol{\theta})$ is zero, the rotor will be aligned with the axis of phase (A). The phase (A) will be switched off, its current $\left(\mathrm{I}_{\mathrm{LA}}\right)$ will be decreased through the load resistance and calculated by;

$$
\left.\mathbf{I}_{\mathbf{L A}}=\mathbf{I}_{\mathbf{f}} \mathbf{e}^{-\left(\mathbf{t}_{\mathbf{A}} / \boldsymbol{\tau}\right.} \mathbf{A}\right)
$$

Where;

$\mathbf{I}_{\mathbf{f}}$ is the higher instantaneous value of excitation current;

${ }_{\mathbf{A}}^{\mathbf{t}}$ is the time from the instant of phase (A) switched off ;

$\boldsymbol{\tau}_{\mathbf{A}}$ is the electrical time constant at any value of rotor angle; or

$\boldsymbol{\tau}_{\mathbf{A}}=\mathbf{L}_{\mathbf{A}} / \mathbf{R}$

The time (t) is calculated at any value of $(\boldsymbol{\theta})$, starting from $\boldsymbol{\theta}=0$ by;

$$
\mathbf{t}=\boldsymbol{\theta} /(\mathbf{6} \mathbf{N})
$$

Where; $\mathrm{N}$ is the rotor speed.

The phase (B) will be switched on at a chosen angle alfa $\left(\boldsymbol{\alpha}_{\mathbf{B}}\right)$ measured from the zero angle of $(\boldsymbol{\theta})$.

The excitation current of phase (B) is calculated by;

$$
\left.\mathbf{I}_{\mathrm{exB}}=\mathbf{I}_{\max }\left[\mathbf{1}-\mathbf{e}^{-\left(\mathbf{t}_{\mathbf{B}} / \tau\right.}{ }_{B}\right)\right]
$$

Where;

${ }^{\mathbf{t}} \mathbf{B}$ is the time from the instant of phase (B) switched on ;

$\boldsymbol{\tau}_{\mathbf{B}}$ is the electrical time constant at any value of rotor angle; or

$$
\boldsymbol{\tau}_{\mathbf{B}}=\mathbf{L}_{\mathbf{B}} / \mathbf{R}
$$

When the rotor is aligned with the axis of phase (B), its phase is switched off. The current of phase (B) is decayed through the load resistance. This current $\left(\mathrm{I}_{\mathrm{B}}\right)$ is calculated by;

$$
\mathbf{I}_{\mathbf{L B}}=\mathbf{I}_{\mathbf{f}} \mathbf{e}^{-\left(\mathbf{t}_{\mathbf{B}} / \tau_{\mathbf{B}}\right)}
$$


After phase (B) is switched off, the phase (C) is switched on at a chosen rotor angle $\left(\alpha_{\mathrm{C}}\right)$ measured from the axis of phase (B) to flow the excitation current of phase (C).

The excitation current of phase $(\mathrm{C})$ is calculated by;

$$
I_{\text {exC }}=I_{\max }\left[\mathbf{1}-\mathbf{e}^{-\left(\mathbf{t}_{\mathrm{C}} / \tau\right.} \mathrm{C}^{\prime}\right]
$$

When the rotor is aligned with the axis of phase (C), its phase is switched off. The current of phase (C) is decayed through the load resistance. This current $\left(\mathrm{I}_{\mathrm{LC}}\right)$ is calculated by;

$$
\left.\mathbf{I}_{\mathrm{LC}}=\mathbf{I}_{\mathbf{f}} \mathbf{e}^{-\left(\mathbf{t}_{\mathbf{C}} / \tau\right.} \mathbf{C}\right)
$$

After phase (C) is switched off, the phase (A) is switched on at a chosen rotor angle $\left(\alpha_{A}\right)$ measured from the axis of phase (C) to flow the excitation current of phase (A). by;

The excitation current of phase (A) is calculated

$$
\left.I_{\text {exA }}=I_{\max }\left[1-e^{-\left(t_{A} / \tau\right.}{ }_{A}\right)\right]
$$

\subsection{Calculation of Generator Power and} Efficiency

The instantaneous value of generator excitation power $\mathrm{P}_{\mathrm{ex}}$ is determined at any value of $\boldsymbol{\theta}$ from the following equation:

$$
P_{\text {ex }}=V_{\text {ph }}\left(I_{\text {exA }}+I_{\text {exB }}+I_{\text {exC }}\right)
$$

The input mechanical power to the generator $\left(\mathrm{P}_{\mathrm{m}}\right)$ is calculated by;

$$
P_{m}=T_{\text {total }}(2 \pi N / 60)
$$

The generator output power to the load $\left(\mathrm{P}_{\mathrm{O}}\right)$ is calculated by;

$$
\begin{aligned}
\mathbf{P}_{\mathrm{O}}=\left(\mathbf{I}_{\mathrm{LA}}{ }^{2} \mathbf{R}_{\mathrm{L}}\right)+ & \left(\mathbf{I}_{\mathbf{L B}}{ }^{2} \mathbf{R}_{\mathbf{L}}\right)+ \\
& \left(\mathbf{I}_{\mathbf{L C}}{ }^{2} \mathbf{R}_{\mathrm{L}}\right)
\end{aligned}
$$

The generator efficiency $(\boldsymbol{\eta})$ is calculated by;

$$
\boldsymbol{\eta}=\mathbf{P}_{\mathrm{O}} /\left(\mathbf{P}_{\mathrm{ex}}+\mathbf{P}_{\mathrm{m}}\right)
$$

\section{TRANSIENT CHARACTERISTICS}

Equations (1-29) are used to compute the transient characteristics of the SRG in the following figures.

The DC excitation voltage is $250 \mathrm{~V}$, and generator speed is 1000 r.p.m. with load resistance per phase of $20 \mathrm{Ohm}$. Figure 8 shows the variation of phase currents with rotor angle at different values of $\boldsymbol{\alpha}$. For $\boldsymbol{\alpha}=0$, the phase (B) current is started at $\boldsymbol{\theta}=$ 0 . This current will be higher, with peak value at $\boldsymbol{\theta}=$ 60. Increasing the value of $\alpha$, leads to decreasing the phase current ( excitation and load currents).

Increasing $\alpha$, leads to decreasing the conduction period. The peak values of load current, load voltage and load power are decreased.

For phase (B) and thus other phases $(\mathrm{C}, \mathrm{A})$, the rotational e.m.f. $\left(\mathrm{E}_{\mathrm{RB}}\right)$ and phase torque $\left(\mathrm{T}_{\mathrm{B}}\right)$ are equal to zero at the switched on angles, due to zero phase current. The values of $\left(\mathrm{E}_{\mathrm{RB}}\right)$ and $\left(\mathrm{T}_{\mathrm{B}}\right)$ are positive through positive $\left(\mathrm{dL}_{\mathrm{B}} / \mathrm{d} \theta\right)$. At switched off angles, $\left(\mathrm{E}_{\mathrm{RB}}\right)$ and $\left(\mathrm{T}_{\mathrm{B}}\right)$ are equal to zero due to the zero value of $\left(\mathrm{dL}_{\mathrm{B}} / \mathrm{d} \theta\right)$. Negative values of $\left(\mathrm{E}_{\mathrm{RB}}\right)$ and $\left(T_{B}\right)$, due to negative $\left(\mathrm{dL}_{\mathrm{B}} / \mathrm{d} \theta\right)$.

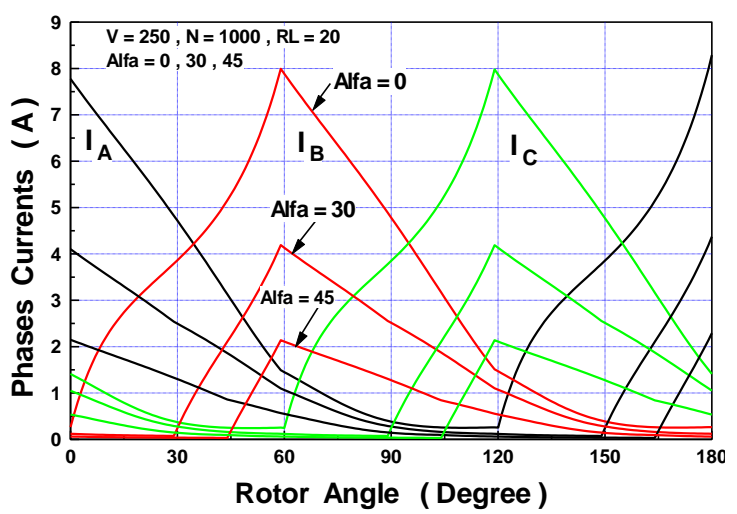

Fig. 8 Variation of phases currents with rotor angle at different values of $\boldsymbol{\alpha}$

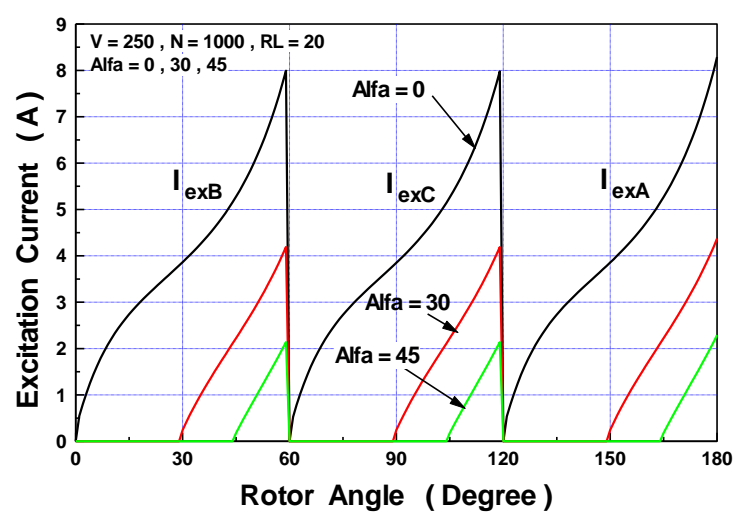

Fig. 9 Variation of excitation current with rotor angle at different values of $\alpha$

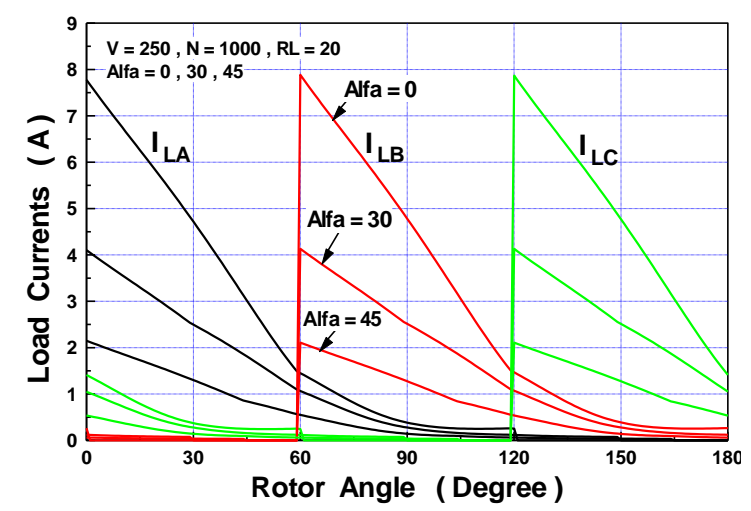

Fig. 10 Variation of load currents with rotor angle at different values of $\boldsymbol{\alpha}$ 


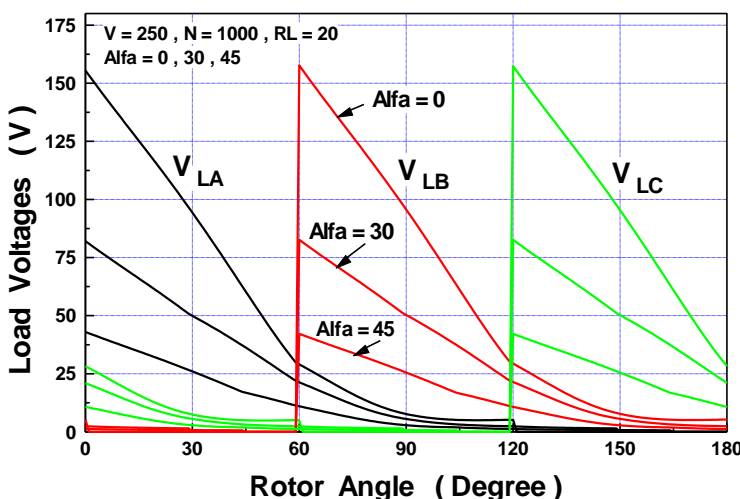

Fig. 11 Variation of load voltages with rotor angle at different values of $\boldsymbol{\alpha}$

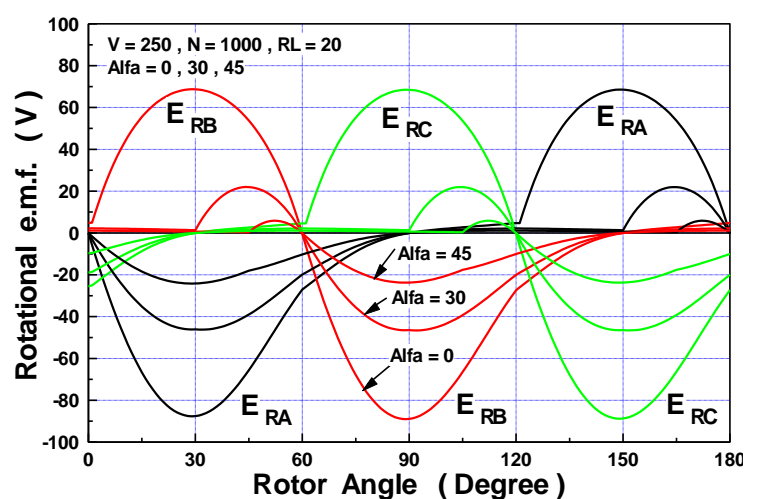

Fig. 12 Variation of rotational e.m.f. with rotor angle at different values of $\alpha$

At the switched on angles, the self e.m.f. for phases $(\mathrm{B}),(\mathrm{C})$ and $(\mathrm{A})$, is a high positive value due to the high positive slop ( $\left.\mathrm{dI}_{\mathrm{B}} / \mathrm{dt}\right)$ as shown in Fig. 13. Through the excitation period, variation of both phase inductance and positive slop $\left(\mathrm{dI}_{\mathrm{B}} / \mathrm{dt}\right)$, leads to positive variable values of self e.m.f. Through the loading period, the slop $\left(\mathrm{dI}_{\mathrm{B}} / \mathrm{dt}\right)$ is negative and thus self e.m.f. is negative.

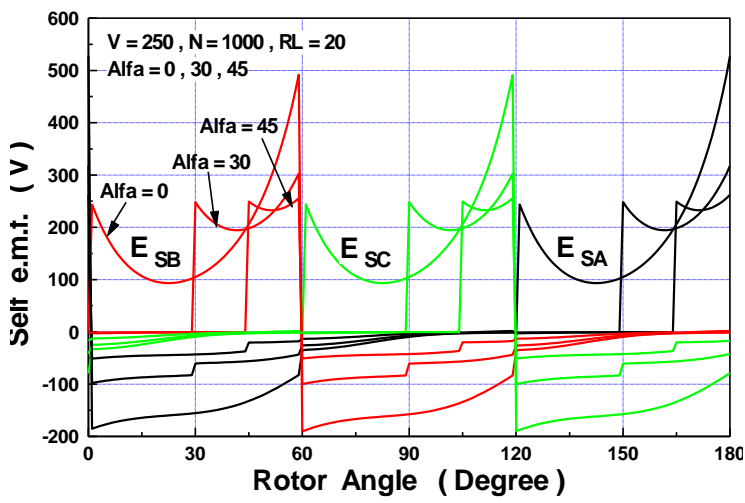

Fig. 13 Variation of self e.m.f. with rotor angle at different values of $\alpha$

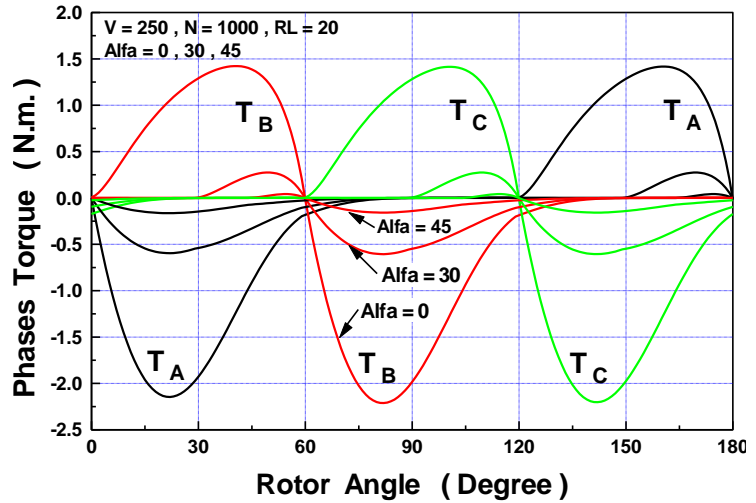

Fig. 14 Variation of phases torque with rotor angle at different values of $\alpha$

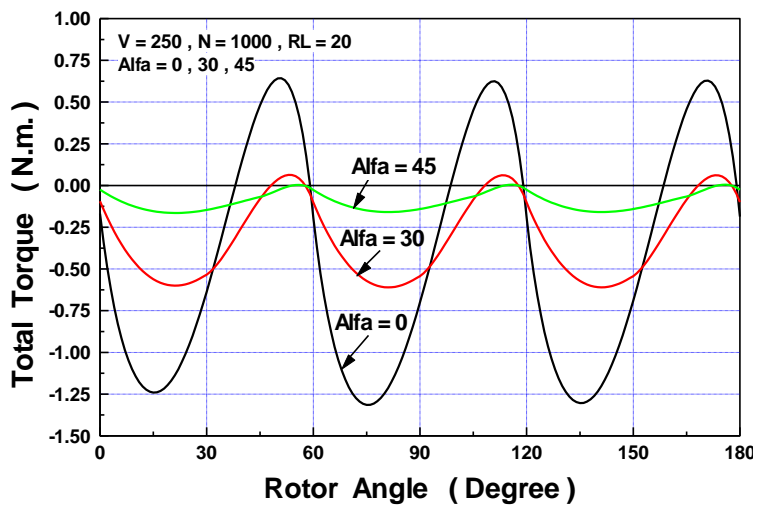

Fig. 15 Variation of total torque with rotor angle at different values of $\alpha$

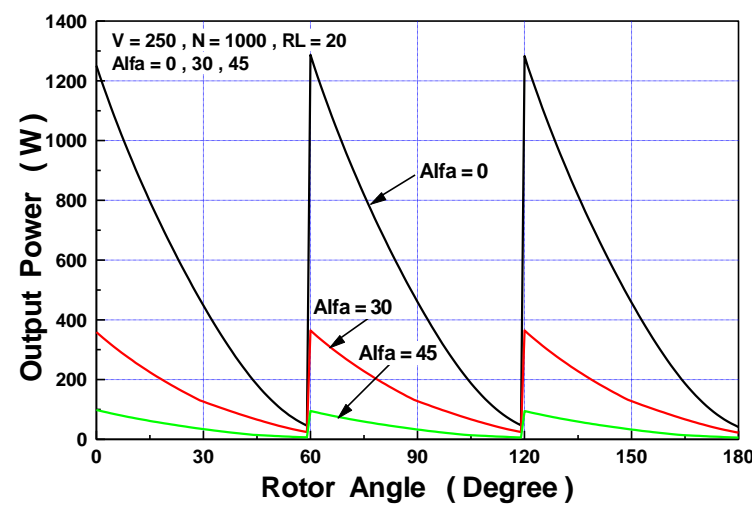

Fig. 16 Variation of output power with rotor angle at different values of $\alpha$

Input power is the summation of excitation power and the negative value of mechanical power due to generating operation. Excitation power is larger than mechanical power due to this low speed (1000 r.p.m.) operation. Speed increasing of this generator to its conventional speed (about 20000 r.p.m.) causes an increasing of prime mover mechanical power than excitation power. The generator efficiency is high at switching on angle and decreased through the switching on period. Increasing the value of $\boldsymbol{\alpha}$ leads to efficiency decreasing as shown in Fig. 18. 
F. M. El-Khouly, A. F. Abdel-Kader, "Transient Characteristics of Cylindrical Stator 6/2 Switched ..."

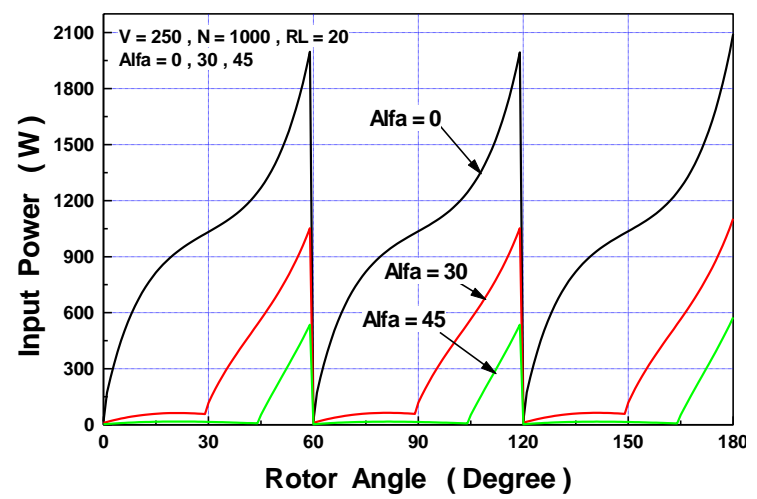

Fig. 17 Variation of input power with rotor angle at different values of $\boldsymbol{\alpha}$

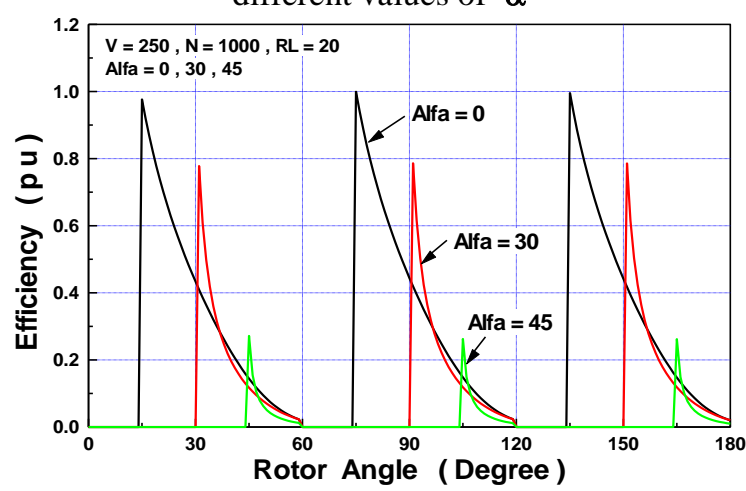

Fig. 18 Variation of generator efficiency with rotor angle at different values of $\alpha$

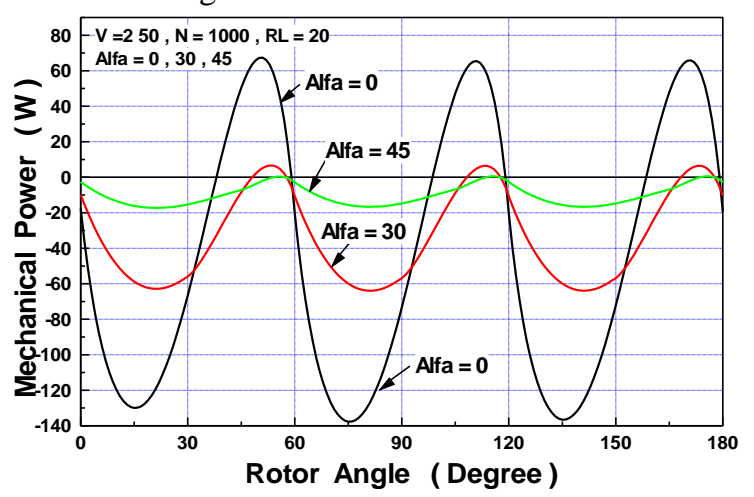

Fig. 19 Variation of mechanical power with rotor

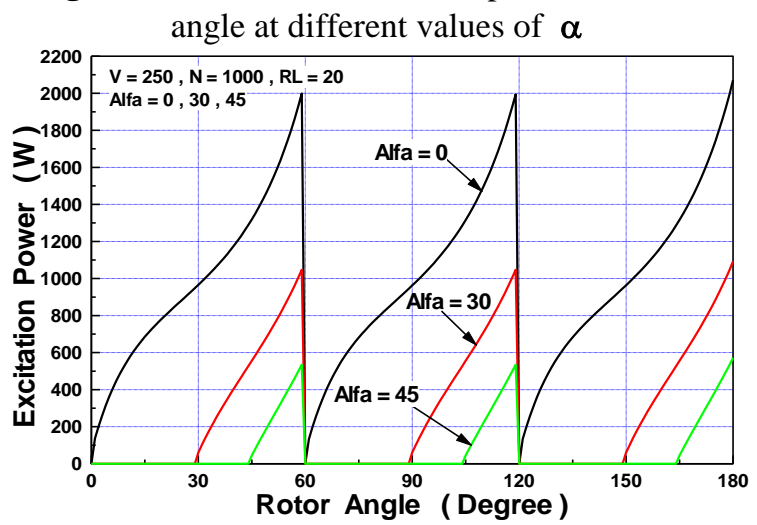

Fig. 20 Variation of excitation power with rotor angle at different values of $\alpha$

\section{EXPERIMENTAL VERIFICATION}

Generator transient characteristics are experimentally measured to verify the computed characteristics. Figures 21, 22 shows the wave forms of load and phase currents at 125, 500 r.p.m. with $\alpha=0$.

The effect of switching on angle $(\boldsymbol{\alpha})$ variation on the wave forms of load and phase currents at 500 r.p.m is shown in Figs. 23 to 25.

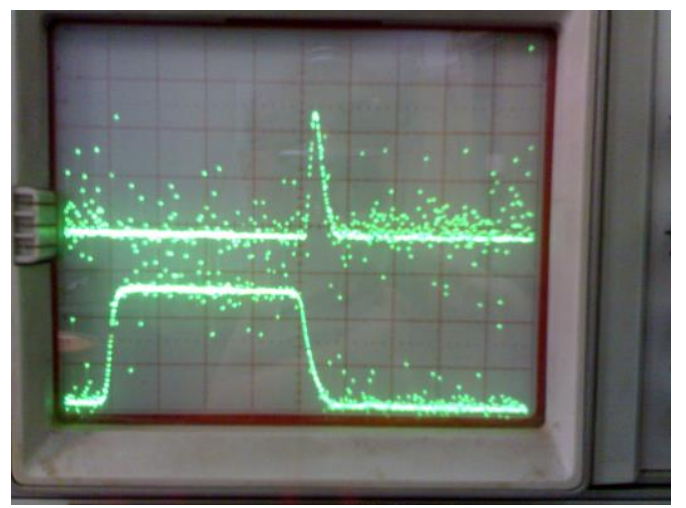

Fig. 21 Wave forms of load Current (Up) and phase current (Down) at $\alpha=0, N=125$ r.p.m., $\mathrm{V}_{\mathrm{ph}}=30 \mathrm{~V}$

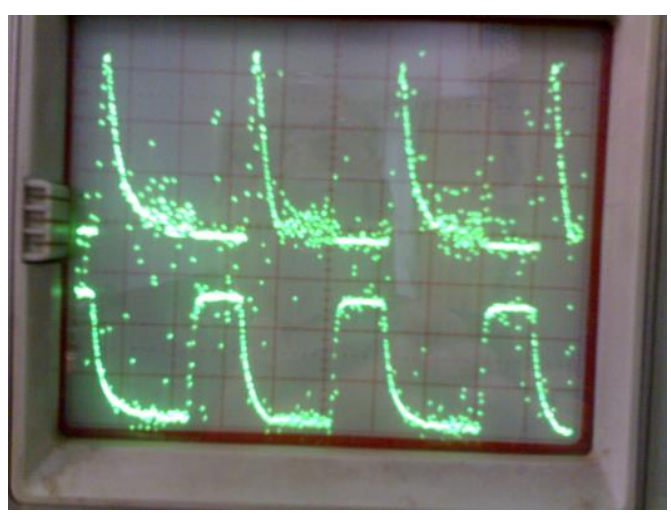

Fig. 22 Wave forms of load Current (Up) and phase current (Down) at $\alpha=0, \mathrm{~N}=500$ r.p.m., $\mathrm{V}_{\mathrm{ph}}=30 \mathrm{~V}$

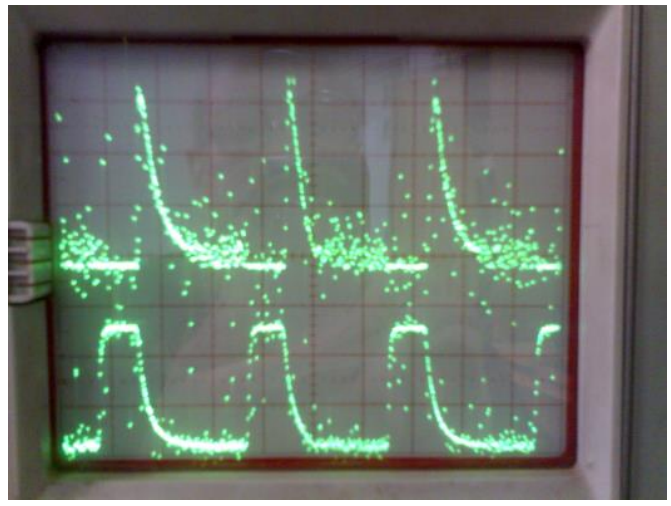

Fig. 23 Wave forms of load Current (Up) and phase current (Down) at $\alpha=15, \mathrm{~N}=500$ r.p.m., $\mathrm{V}_{\mathrm{ph}}=30 \mathrm{~V}$ 


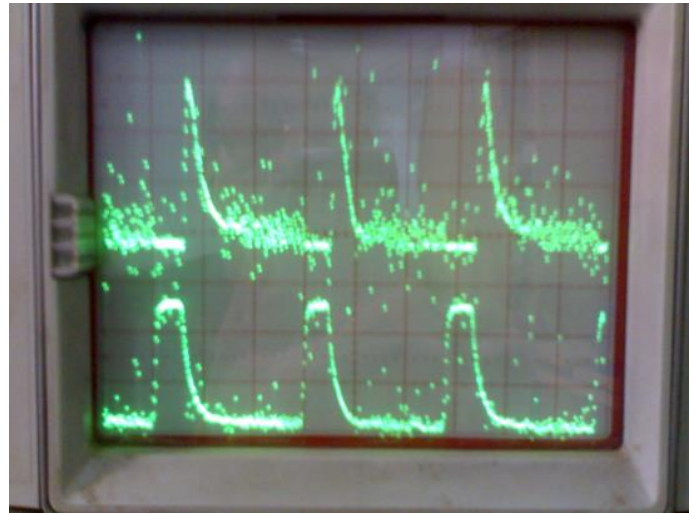

Figs. 24 Wave forms of load Current (Up) and phase current (Down) at $\boldsymbol{\alpha}=30, \mathrm{~N}=500$ r.p.m., $\mathrm{V}_{\mathrm{ph}}=30 \mathrm{~V}$

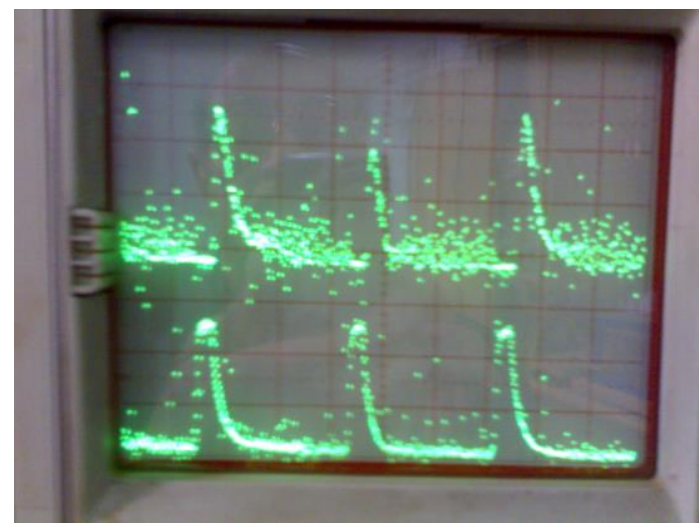

Fig. 25 Wave forms of load Current (Up) and phase current (Down) at $\alpha=45, \mathrm{~N}=500$ r.p.m., $\mathrm{V}_{\mathrm{ph}}=30 \mathrm{~V}$

\section{CONCLUSIONS}

More accurate simulation of generator phase self inductance when its variation is approximated by a sinusoidal wave instead of triangular shape added to a constant value. It is preferred to reduce the switch on period to decrease the excitation power.

The result of this investigation into the nature of the excitation of the SRG has been presented. Detailed generator transient characteristics have been obtained from the corresponding computed analysis. Measured phase current and load current wave forms taken on the experimental SRG are presented to verify the theoretical results.

Output power and its rate of change depend on the operating speed, switching on angle and excitation voltage. Optimal turn on angle is on the increasing slope of phase self-inductance, and optimal turn off angle is on the aligned value of phase self-inductance.

The prototype built and the results obtained confirm that the mathematical analysis is accurate. The cylindrical stator of the built generator is more simple and conventional in the manufacturing process.

\section{REFERENCES}

[1] S. R. MacMinn and J. W. Sember, "Control of a switched-reluctance aircraft starter/generator over a very wide speed range," in Proc. Intersociety Energy Conversion Engineering Conf., 1989, pp. 631-638.

[2] C.A Ferreira., S.R Jones, W.S. Heglund, W.D. Jones, "Detailed design of a $30-\mathrm{kW}$ switched reluctance starter/generator system for a gas turbine engine application" Industry Applications, IEEE Transactions on, Volume: 31 , Issue: 3 , May-June 1995

[3] M.A Mueller, "Design of low speed switched reluctance machines for wind energy converters"; Electrical Machines and Drives, 1999. Ninth International Conference on (Conf. Publ. No. 468), 1-3 Sept. 1999 Pages:60 - 64

[4] R. Cardenas, W. F. Ray, and G. M. Asher, "Switched reluctance generators for wind energy applications," in Proc. IEEE PESC'95, 1995, pp. 559-564.

[5] B. Fahimi, A. R.B. Emadi, Jr. Sepe, "A switched reluctance machine based starter/alternator for more electric cars" Energy Conversion, IEEE Transactions on, Volume: 19, Issue: 1, March 2004 Pages: 116 - 124

[6] A. Radun, "Generating with the switchedreluctance motor," in Proc. IEEE APEC'94, 1994, pp. 41-47.

[7] Y. Sozer, D.A. Torrey, "Closed loop control of excitation parameters for high speed switchedreluctance generators", Power Electronics, IEEE Transactions on , Volume: 19, Issue: 2 , March 2004 Pages: $355-362$

[8] Asadi, P.; Ehsani, M.; Fahimi, B., "Design and control characterization of switched reluctance generator for maximum output $\mathrm{p}$ ower", Twenty-First Annual IEEE Conference and Exposition on Applied Power Electronics, APEC'06, 19-23 March 2006,Pages:1639-1644.

[9] B. Fahimi, S. Dixon, "Enhancement of output electric power in switched reluctance generators", Electric Machines and Drives Conference, 2003, IEMDC'03. IEEE International, Volume: 2, 1-4 June 2003 Pages: 849 - 856 vol. 2

[10] Asadi, P.; Ehsani, M.; Fahimi, B., "Design and control characterization of switched reluctance generator for maximum output power", TwentyFirst Annual IEEE Applied Power Electronics Conference and Exposition, 2006, APEC '06, 19-23 March 2006, Pages: 1639-1644 
F. M. El-Khouly, A. F. Abdel-Kader, "Transient Characteristics of Cylindrical Stator 6/2 Switched ..."

[11] Nassereddine, M.; Rizk, J.; Nagrial, M.; Hellany,A., "Study analysis on the excitation of a switched reluctance generator for wind energy conversion", International Conference on Advances in Computational Tools for Engineering Applications, 2009, ACTEA '09, 1517 July 2009, Pages:112-116.

[12] Fleury, A.; Andrade, D.; Silveira, A.W.F.V.; Ribeiro, F.S.L.; Coelho, "Dependence of the switched reluctance generator output on the speed and the excitation voltage", 34th Annual Conference of IEEE Industrial Electronics, IECON 2008, 10-13 Nov. 2008 Pages:1101-1105

[13] Takahashi, Atsushi; Goto, Hiroki; Nakamura, "Characteristics of 8/6 SR Generator with a Suppression Resistor Converter", 12th International Conference on Power Electronics and Motion Control, EPE-PEMC 2006, Aug. 30 2006-Sept. 12006 Pages:1037 - 1041

\section{APPENDIX}

Experimental Machine Parameters

$\mathrm{Rph}=4 \mathrm{Ohm}$

$\mathrm{R} \mathrm{L}=20 \mathrm{Ohm}$

$\mathrm{L} \mathrm{d}=0.29$ Henary

L q $=0.09$ Henary

Stator Phases $=3$

Stator Cylindrical Poles $=6$

Rotor Salient Poles $=2$ 